\title{
Kalça bölgesi tuzak nöropatileri
}

\section{Entrapment neuropathies around the hip}

\author{
Kıvanç Muratıı', Şükrü Araç² \\ 'Başkent Üniversitesi Tıp Fakültesi, Ortopedi ve Travmatoloji Anabilim Dalı, İzmir \\ ${ }^{2}$ Başkent Üniversitesi, Zübeyde Hanım Hastanesi, İzmir
}

Kalça bölgesi tuzak nöropatileri, ağrı, duyusal kayıp veya anormaliteler yanı sıra, sıklıkla aksama ve fonksiyonel kayıp ile karakterizedir. Radikülopati kliniği ile karıştırılabilmesi nedeniyle, tanı konulması zor ve sıklıkla atlanabilen patolojilerdir. Bu nöropatilerin tanısında, gelişmiş tanı yöntemleri kadar, hekimin nöroanatomiye olan hakimiyeti de önemlidir. Bu yazıda, kalça bölgesinde sık görülen tuzak nöropatiler, anatomik ve patolojik faktörler açısından gözden geçirilmiştir.

Anahtar sözcükler: tuzak nöropati; kalça; siyatik sinir; femoral sinir
Entrapment neuropathies of the hip region are characterized by pain, sensory loss or abnormalities, as well as limping and functional loss. These disorders may be confused with radiculopathy in clinical examinations; therefore diagnoses are often difficult and are frequently overlooked. As well as the improved diagnostic methods, clinical experience and mastering neuroanatomy are also important. In this paper, common entrapment neuropathies around the hip were reviewed in terms of anatomical and pathological factors.

Key words: nerve entrapment; hip; sciatic nerve; femoral nerve
D) eriferik sinirlerde oluşan tuzak nöropatiler, basınca maruz kalma, gerilme, açılanma ve sürtünme gibi değişik mekanizmalar ile oluşabilir. Bir sinirin belirli bir bölgede basınca maruz kalması; kalınlaşmış ve/veya gergin bir fibröz veya fibro-osseöz anatomik yapı, anormal morfolojideki ya da hipertrofiye olmuş bir kas yapısı, skar dokusu, yumuşak doku ödemi, kemik deformitesi veya tümöral nedenlerle oluşabilir. Sinir dokudaki hasar, kısa süreli yüksek basınca maruz kalma durumunda olduğu gibi, uzun süreli düşük basınca maruz kalma durumunda da oluşabilir. Kemik yapılardaki deformite, kırık veya çıııklarda olduğu gibi, sinir dokunun gerilmesi veya açılanması gibi durumlar da benzer sonuçlara yol açmaktadır.

Periferik sinirlerde kompresyon ve gerilmeye ek olarak, sinir hasarının önemli bir nedeni de iskemidir. Örneğin; intraabdominal ve pelvik cerrahi sırasında oluşan iskemik durumlar, arteriyel kanülasyon veya cerrahi sonrası oluşan hematomlar, hem basınç hem de iskemi yoluyla sinir hasarına neden olabilir.

Cerrahiye bağlı sinir problemleri, cerrahi alanda veya komşuluğunda olan sinirlerin, direkt travmaya, basınca veya gerilmeye bağı olması sonucu görülebildiği gibi, hastanın pozisyonuna bağlı da oluşabilir. Örneğin; litotomi pozisyonunda, kalçanın fleksiyon ve abduksiyon pozisyonunda olması nedeniyle, femoral ve obturator nöropatiler bildirilmiştir. ${ }^{[1-3]}$ Benzer şekilde, kalça eklem bölgesinde eski kırk, heterotropik ossifikasyon gibi nedenlerle deformite olan hastalarda da, litotomi pozisyonu sonrasında siyatik sinir lezyonu bildirilmiştir. ${ }^{[1,4]}$

Total kalça artroplastisi ile birlikte, cerrahi travma, kanama, gerilme, kemik çimentosu içine gömülme veya kemik çimentosu tarafindan deplase edilme ya da sıkıştırılma gibi nedenlerle, siyatik, femoral ve obturator sinir lezyonları bildirilmiştir. ${ }^{[5]}$

Kalça bölgesinde, cerrahi uygulamalar sonucu oluşan sinir lezyonlarına verilebilecek diğer örnekler arasında; özellikle iliak kemik grefti alınması, kasık flebi uygulaması sırasında veya sonrasında oluşan lateral femoral kutanöz sinir lezyonu sonucu görülen meraljia parestetika ve inguinal herni onarımı gibi alt abdominal ve jinekolojik cerrahi sonrasında oluşabilecek iliohipogastrik, ilioinguinal ve genitofemoral sinir lezyonları da sayılabilir.

- İletişim adresi: Prof. Dr. Şükrü Araç, Başkent Üniversitesi, Zübeyde Hanım Hastanesi, İzmir 
Kalça bölgesi tuzak nöropatilerin kliniği, oldukça kafa karıştıııcıdır ve klinik olarak tanı konulması zor olabilmektedir. Geçmişte, bu nöropatilerin tanısında asıl dayanak noktası elektrofizyolojik çalışmalardı. Ancak günümüzde, özellikle manyetik rezonans (MR) görüntülemedeki ilerlemeler, yüksek çözünürlüklü kesitsel incelemeler ve MR nörografi ile birlikte, tuzak nöropatilerin tanısında MR görüntülemenin rolü giderek artmaktadır.

\section{MR GÖRÜNTÜLEME}

MR görüntülemede, sinir dokunun sinyal yoğunluğu, çapı/büyüklüğü, morfolojisi ve konumundaki değişikliklerden, nöral bir patoloji olup olmadığı anlaşılabilmektedir. Motor sinirlerdeki patolojiler nedeniyle oluşan, kaslardaki denervasyon bulguları gibi ikincil belirtilerin varlığı durumunda, nöral hastalık veya yaralanma gibi durumlar akla getirilmelidir. Karma motorduyu sinirlerinin etkilenmesi durumunda ise, genellikle duyusal belirtiler baskın olduğundan, MR görüntülemede ikincil bulgular görülmeyebilir.

Normal sinirler, T1 ağırlıklı görüntülerde orta sinyal yoğunluğunda ve T2 ağırlıklı görüntülerde kas dokusuna göre izointens veya hafif hiperintens görülür. T2 ağırlıklı nörografi, uzun eko değerlerine sahip (en az 90 milisaniye) sekansları, radyofrekans satürasyon atımlı sekanslar ile komşu damar yapılarından gelen sinyallerin baskılanması ve frekans seçici yağ baskılama yoluyla gerçekleştirilir. ${ }^{[6]}$ Bununla birlikte, sinir dokusu içindeki artmış sinyal yoğunluğu, her zaman altta yatan bir patolojiyi göstermez. Brakiyal ve lumbosakral pleksuslarda görülen sihirli açı etkisi veya artefaktı (ana manyetik alana belirli bir açıda dizilim gösteren bölgelerin hiperintens görüntülenmesi durumu), periferik sinir görüntülemesinde de tanımlanmıştır. ${ }^{[6,7]} \mathrm{Bu}$ nedenle, özellikle sinir dokudaki artmış sinyal intensitesinin görülebilen tek patolojik bulgu olması durumunda, bu tür açıya bağlı sinyal değişiklikleri düşünülmelidir.

MR görüntülemede gözlemlenebilecek indirekt bulgular ise, genellikle motor nöropatilerde karşımıza çıkmaktadır. Akut kas denervasyonunun erken dönemlerinde kas dokusu, T1 ağırlıklı kesitlerde normal görünümde iken, sıvı duyarlı sekanslarda ekstrasellüler kompartmanda sıvı artışı ve kapiller yatağın genişlemesi ile, kan hacminde artışa bağlı olarak hiperintens görünümdedir. Bu dönemde, fasya ve cilt altı dokularda anormallik gözlenmez ve kas dokusunun hacmi normaldir. Denervasyon ilerledikçe, hem T1 hem de sIvı duyarlı sekanslarda, sinyal intensitesinde artış görülür; T1 sekansındaki bu intensite artışı, denervasyona bağlı kas artofisi olarak yorumlanır. Takip eden dönemlerde, kas hacminde giderek azalma ve yağ dokusu ile yer değiştirme izlenir.

\section{SIYATIK SINIR}

Siyatik sinirin tuzak nöropatisi, tek başına nadir görülen bir durumdur. Siyatik sinir alanında semptomları olan birçok hastada, lomber omurga patolojileri eşlik etmektedir.

L4-S3 sinir köklerinden köken alan siyatik sinir, tibial ve peroneal kısımları bir bütün olarak siyatik çentikten geçerek, pelvisten çıkar. Bu noktada piriformis kasının altından geçer ve internal obturator kasının önünden seyreder. Siyatik sinir, gluteus maksimus kasının anteriorunda ve adduktor magnus adalesinin posteriorunda distale doğru ilerlemeye devam eder ve femoral bölgenin distal 1/3'lük kısmında, tibial ve ortak peroneal dallara ayrılır. Siyatik sinir, posterior uyluk kaslarının innervasyonunu ve diz altındaki hemen hemen tüm duyu ve motor fonksiyonları sağlar. Ortak peroneal sinir, anterior ve kruris lateral bölgenin, tibial sinir ise kruris posterior bölgesi ve plantar kasların tüm motor fonksiyonunu sağlar.

Sinirin büyüklüğü ve çevresindeki perinöral yağ dokusunun geniş olması nedeniyle, MR görüntülemeyle inceleme kolay olur.

Siyatik sinir, diz fleksörleri ve diz altındaki tüm kas gruplarını innerve eder. Siyatik nöropatide, sartorius ve grasilis kaslarının fonksiyonları korunmuş ise, dizde fleksiyon hareketi sağlanabilir. Ayrıca, kalça fleksiyonu (lezyon, hamstring dallarının proksimalinde ise) ve adduksiyonu ile, ayak bileği ve ayak seviyesindeki tüm hareketler ve Aşil tendon refleksi etkilenir. Bu nedenle, tam siyatik sinir felci, ileri yürüme güçlüğü ve fonksiyon kaybına neden olur. Bununla birlikte, tam siyatik sinir felci nadir görülür. Peroneal kısmının liflerinin daha yüzeyel, destekleyici bağ dokusunun daha az ve tibial kısmının tek noktada (siyatik çentik) fikse olmasına karşın; peroneal kısmının iki noktada (siyatik çentik ve fibula başı) fikse olması nedeniyle, sıklıkla peroneal kısım etkilenir.

Siyatik sinir tuzak nöropatisi en sık kalça bölgesinde görülürken, femoral bölgede daha az sıklıkta ortaya çıkabilmektedir. Kalça bölgesinde görülen siyatik tuzak nöropatinin en sık nedeni iyatrojenik olup; bu nöropati, total kalça artroplastisi sırasında gerilme veya sinirin direkt travmaya maruz kalması sonucunda oluşmaktadır. Piriformis sendromu, siyatik nöropatinin bir nedeni olup, ayrı bir başlık altında incelenmiştir. Siyatik mononöropatisi etiyolojisinde yer alan bazı faktörler, Tablo 1'de sıralanmıştır.

Kalça artroplastisi başta olmak üzere, kalça bölgesi cerrahilerinde sinirin gerilme veya direkt travmaya maruz kalmasının dışında; kanama, hematom ve kemik çimentosu sızıntılarına bağlı siyatik sinir lezyonları görülebilmektedir. Weber ve arkadaşları, ${ }^{[5,8]}$ kalça 
Tablo 1. Siyatik sinir mononöropatisi etiyolojik faktörler[25]

Koristoma
Endometriosis
Eksternal kompresyon
Femur kırığı
Ateşli silah yaralanması
Antikoagülan kullanımına bağlı hematom
Intramusküler enjeksiyon
Total kalça artroplastisi
Kalça kırığı/çıkığı
Idiyopatik
Infarkt
Lipomatöz infiltrasyon
Nörilemmoma
Travma
Tümörler
Uterin kompresyon

artroplastisi uygulamalarının çoğunda, subklinik olmakla birlikte, anormal elektromiyografi (EMG) sonuçları gözlendiğini bildirmişlerdir. EMG kriterlerine göre, hastaların \%70'inde subklinik siyatik hasar görülebilmektedir. Schmalzreid ve arkadaşları, ${ }^{[9]} 3126$ total kalça artroplastisi uygulamasında yaptıkları incelemede, siyatik nöropati prevalansını \%1,7 olarak saptamışlar ve revizyon olguları ile uzatma uygulanan olgularda, riskin daha yüksek olduğunu belirtmişlerdir. Bununla birlikte, birçok yazar, en sık nedenlerin kalça artroplastisi sırasında pozisyon ve gerilme olduğu konusunda hemfikirdir.

MR görüntülemede sinirin çapında ve sinyal yoğunluğunda artış, sinir trasesinde sapma gibi bulgular, siyatik sinir nöropatisi açısından kanıt niteliğindedir. Anormal sinyal artışı, siyatik sinirin büyüklüğü nedeniyle, diğer alt ekstremite sinirlerine göre daha kolay tespit edilir. Sinirin çevresinde, tümöral doku, skar, tendinöz patolojiler veya fibrotik dokular gibi yumuşak doku anormallikleri, hematom, ödem gibi durumlar da kolay bir biçimde saptanabilir. Proksimal tutulumlu lezyonlarda, uyluk ve hamstring kasları yanı sıra adduktor magnus ve hamstring bileşenini içeren, denervasyon ile uyumlu sinyal intensite değişiklikleri görülebilir. Ancak, sıklıkla sinir tutulumunun daha distal seviyede olması nedeniyle, etkilenen kas gruplarının diz seviyesinden distalde olması sonucu, denervasyona bağlı bulgular, kalça bölgesinin rutin MR incelemelerinde saptanamaz.

Siyatik sinir tuzak nöropatisinin elektrofizyolojik incelemesinde en önemli nokta, siyatik sinir tuzak nöropatisinin daha sık görülen kök sıkışma sendromlarından ayrılmasıdır. Bu amaçla, iğne elektrodlar kullanılarak uygulanan çeşitli motor sinir ileti teknikleri, ortodromik sensöriyel ileti, sakral kök stimülasyon teknikleri ve somatosensöriyel uyarılmış potansiyel (SSEP) teknikleri tanımlanmıştır.

Klinik olarak ayırıcı tanıda, lomber disk herniyasyonu ve spinal stenoz gibi spinal patolojilerin yanında, özellikle diyabetik nöropati gibi vasküler nöropati nedenleri de düşünülmelidir. Ayrıca, intraspinal karsinom, lenfoma veya miyelom gibi patolojiler de akılda tutulmalıdır.

\section{PIRIFORMIS SENDROMU}

Piriformis sendromu, siyatik sinirin piriformis kası tarafından kompresyona uğraması sonucu oluşan bir tuzak nöropatidir. Illk olarak Yeoman ${ }^{[10-12]}$ tarafindan 1928'de tanımlanmış, ancak 1947'de Robinson ${ }^{[13]}$ tarafindan, "piriformis" veya piramidal sendrom olarak adlandırılmıştır. Bel ağrısı olan olgularda piriformis sendromunun insidansı, çok değişken düzeylerde bulunmuş olup, \%5-36 arasında bildirilmiştir. ${ }^{[14-16]}$ Sıklıkla tanısının atlanması veya diğer patolojilerle karıştırılması nedeniyle, gerçek prevalansı bilinmemektedir. Priformis sendromu, primer ve sekonder olmak üzere iki gruba ayırılabilir. Primer grubun etiyolojisinde, anatomik varyasyonlar veya anormal ataşmanlar, ödem veya hipertrofiye bağlı dinamik sıkışma ve siyatik sinirin anormal trasede seyretmesine bağlı anomaliler gibi durumlar sayılabilir. Sekonder grupta ise, cerrahi sonrası fibrozis, avulsiyon, strain, tendinozis, kalsifik tendinit veya spazm gibi durumlara yol açan travma veya aşırı kullanım zedelenmeleri benzeri, tetikleyici faktörler söz konusudur. ${ }^{[14]}$

Semptomlar, genellikle nonspesifiktir ve sinirin derin bir konumda seyretmesi nedeniyle elektrodiyagnostik testlerin uygulanması zor olduğundan, piriformis sendromu tanısı kolay konulamayabilir. Martin ve arkadaşları, ${ }^{[17]}$ gluteal bölgede siyatik sinir sıkışması ile ilgili klinik testlerin tanısal doğruluğunu incelemişler ve aktif piriformis testi ve oturur pozisyonda piriformis germe testinin kullanılabileceğini bildirmişlerdir. Michel ve arkadaşları, ${ }^{[10,11]}$ piriformis sendromunun tanısında bir altın standart olmadığını; ancak, fleksiyon-adduksiyon-internal rotasyon (FAIR) manevrası ile uyarılmış uyarı-algılama yöntemi ile elektrofizyolojik incelemenin anlamlı sonuçlar verebileceğini bildirmişlerdir. 
Piriformis sendromunun görüntüleme yoluyla tanısı da benzer şekilde sorunludur. Sinirdeki değişiklikler tanıyı akla getirebilmekle birlikte, piriformis kasındaki değişiklikler ve karşı taraf ile karşılaştırılma, daha az güvenilir bilgiler vermektedir. Russell ve arkadaşla$r_{1},{ }^{[18]}$ piriformis sendromu öyküsü veya klinik şüphesi olmayan 100 hastadan oluşan bir seride, hastaların \%81'inde kas büyüklüklerinde $2 \mathrm{~mm}$ asimetri mevcut olduğunu saptamış, $4 \mathrm{~mm}$ veya daha fazla asimetrisi olan hastaların hiçbirinde piriformis sendromu düşündüren bulgulara rastlanmadığını bildirmişlerdir. Filler ve arkadaşları, ${ }^{[19]}$ piriformis cerrahisinden yarar gördügü belirlenen hastalarda MR nörografi kullanarak yaptıkları çalışmada, tek başına kas asimetrisinin duyarlılığının \%46 ve özgüllüğünün \%66 olmasına karşın, kas asimetrisine ek olarak sinir sinyal intensitesinin birlikte değerlendirilmesi durumunda, \%64 duyarlılık ve \%93 özgüllük değerleri bildirmişlerdir.

Piriformis sendromu tedavisi, öncelikle konservatif olup, anti-inflamatuvar ilaçlar, fizik tedavi ve görüntüleme eşliğinde kas içine kortikosteroid enjeksiyonu yöntemlerini içerir. Altta yatan süreç, musküler kompresyon ile ilgilidir ve bu mekanizmadan yola çıkarak, botulinum toksin A kullanımı ile umut verici sonuçlar bildirilmiştir. ${ }^{[20]}$ Dirençli olgularda, piriformis kasının cerrahi olarak gevşetilmesi düşünülebilir. Martin ve arkadaşları, ${ }^{[21]}$ yaptıkları çalışmada, siyatik sinir tuzak nöropatisi saptanan 35 olguda, endoskopik dekompresyon ile olumlu sonuçlar bildirmişlerdir.

\section{FEMORAL SINIR}

Femoral sinir, karma bir motor ve duyusal sinir olup, lomber pleksusun en büyük dalıdır. L2-L4 köklerinden başlayarak, psoas kasını innerve eder. Femoral sinir, pelvis içinde, iliakus kompartmanından geçerek, inguinal bağın yaklaşık $5 \mathrm{~cm}$ proksimalinde iliakus ve psoas kaslarına dallar verir. Uyluk proksimalinde, sartorius, pektineus ve kuadriseps grubuna dallar verir. Uyluk anterior ve mediyalinin duyusunu sağlayan kutanöz dalları verir ve distalde de kruris bölgesinin anterior ve mediyal kısmının duyusunu sağlayan safen siniri oluşturur. Femoral sinirin motor fonksiyon bozukluğu, etkilenen düzey ile ilişkilidir. Proksimal seviyeli lezyonlarda kalça fleksiyonu etkilenirken, inguinal bağ seviyesindeki lezyonlarda kalça fleksiyonu korunmuş olup, problem daha çok diz ekstansiyonu ile ilişkilidir. Bu durumda, hasta, dizini ekstansiyona getirmede ve orada kilitlemede zorluk çeker. Bu durum, dizde instabilite ve denge kaybına yol açar. Femoral nöropatisi olan hastalarda, sıklıkla kuadriseps grubunda atrofi, patellar tendon refleksinde kayıp, uyluk anterior ve mediyalinde, ayrıca kruris mediyalinde duyu kusuru bulunur. Femoral nöropati, klinik olarak lomber pleksus patolojisi ve L4 radikülopatisi ile karışabilir.

Femoral sinirin zedelenmeye en açık olduğu bölge, iliakus kompartmanındadır. Femoral sinir tuzak nöropatilerinin çoğu, iliopsoas kompartmanındaki travmalar sonucu oluşan iliakus veya iliopsoas kaslarının yırtılması ve hematomlara bağlı gelişmektedir. [22-24] Femoral sinir sıkışması ve nöropatisi, ayrıca, abdominal cerrahi, jinekolojik cerrahi, femoral arteriyel kataterizasyon, litotomi pozisyonu, inguinal bölgede veya retroperitoneal alanda hematom, pelvik kırıklar, total kalça artroplastisi gibi durumlarda da görülebilir (Tablo 2).

Femoral sinirin, büyük boyutlarına rağmen, MR görüntülerinde belirlenmesi zor olabilir. İntrapelvik seyri boyunca iliakus kompartmanında iken, femoral arter ve venin hemen lateralinde, psoas ve iliakus kasları arasında bir oluk içinde yer alır. İnguinal bağ seviyesinde, koronal görüntülerde görülebilir. Sinyal yoğunluğu ve sinirin trasesindeki değişimleri, intrapelvik kısmında

Tablo 2. Femoral mononöropati etiyolojik faktörler ${ }^{[25]}$

Abdominal pelvik cerrahi

Amiloidozis

Künt travma

Koroner anjiyografi

Femoral asetabular impingement

Femoral sinir bloğu

Kist hidatid

İyatrojenik

İlioinguinal/iliohipogastrik sinir bloğu

Laparoskopik cerrahi

Litotomi pozisyonu

Lefomatöz kompresyon

Pelvik ekstraperitoneal hematom

Postpartum

Psoas kas hematomu

Böbrek yetmezliği

Böbrek transplantasyonu

Retroperitoneal hematom

Rabdomyolizis

Total kalça artroplastisi

Ürolojik cerrahi

Vaskülit 
tespit etmek daha kolaydır. Uyluk bölgesinde, sinirin küçük boyutu nedeniyle, bu değişikliklerin saptanması nispeten daha zordur. iliopsoas kasında denervasyon ile uyumlu sinyal yoğunluğu değişikliklerinin saptanması, intrapelvik femoral sinir lezyonunu düşündürmelidir (proksimal psoas kası doğrudan L2 ve L3 sinir kökleri tarafından innerve edilir).

Femoral sinir tuzak nöropatisinde cerrahi tedavinin komplikasyonları çok ciddi sonuçlara yol açabilir. Bu nedenle, tedavide öncelikle konservatif yöntemler denenmelidir.

\section{SUPERIOR GLUTEAL SINIR}

Superior gluteal sinir, L4, L5, S1 ve dorsal köklerinden başladıktan sonra siyatik çentikten geçerek, piriformis kasının proksimaline doğru ilerler. Superior dalı gluteus minimus kasını innerve ederken, inferior dalı ise gluteus medius, minimus ve tensor fasya lata kaslarına dağılır. Superior gluteal nöropati nedenleri arasında; piriformis kası hipertrofisi, herediter multipl ekzostozis, piriformis tendonlarına bağlı tuzak nöropati, total kalça artroplastisi, intramusküler enjeksiyon ve cerrahi uygulama amaçlı, uzun süreli lateral dekubit pozisyonu gibi etkenler bildirilmiştir. ${ }^{[25]}$ Superior gluteal sinir zedelenmesinin en çok karşılaşılan ve bilinen nedeni, total kalça artroplastisi uygulamasıdır. Özellikle, kalçaya direkt lateral yaklaşımda inferior dalı, anterolateral yaklaşımda ise tensor fasya lata kasına verdiği dallar risk altındadır. Total kalça artroplastisi uygulanan hastalarda, cerrahi yaklaşım tekniğinden bağımsız olarak, \%77'lere varan oranlarda subklinik elektrofizyolojik bulgular bildirilmiştir. ${ }^{[26]}$ Bu durum, genellikle bir yıl içinde kendiliğinden düzelir. Superior gluteal sinir yaralanması, aynı zamanda, perkütan iliosakral vida uygulamasının iyi bilinen bir komplikasyonudur. ${ }^{[27]}$

Klinik olarak, hastalarda, temel olarak kalça abduksiyonunda zayıflığa bağlı olarak aksama ve trendelenburg belirtisi görülebilir. Ayrıca, elektrofizyolojik incelemelerde, superior gluteal sinir patolojisi saptanabilir. MR görüntülemede ise, superior gluteal sinir, genellikle pelvisi terk ettiği seviyede, koronal ve sagittal kesitlerde görülebilir, ancak yakın komşuluğundaki vasküler yapılardan ayırt edilmesi gerekir. MR görüntülemede superior gluteal sinirin incelenmesi zordur ve bulgular daha çok, gluteus medius, minimus ve tensor fasya lata gibi innerve ettiği kaslardaki denervasyon bulgularını içerir.

\section{INFERIOR GLUTEAL SINIR}

Inferior gluteal sinir, L5, S1, S2 seviyelerinin dorsal dallarından köken alır. Gluteus maksimus kasının ana motor siniri olan inferior gluteal sinir, siyatik sinirin mediyalinde seyrederek, siyatik çentik seviyesinde pelvisi terk eder; piriformis kasının alt sınırında posteriora doğru dönerek, gluteus maksimus kasını innerve eden çoklu dallarına ayrıı. İnferior gluteal sinir, ayrıca, posterior femoral kutanöz sinire dal verebilir.

İnferior gluteal sinirin tuzak nöropatisi, nadiren görülmekle birlikte, genellikle posterior yaklaşımla uygulanan kalça artroplastisinin bir komplikasyonu olarak bilinir. Inferior gluteal sinir disfonksiyonunda; gluteus maksimus kasında atrofi, gluteal kıvrımda silikleşme, kalça ekstansiyonunda ciddi güç kaybı ile birlikte, oturduğu yerden kalkma ve merdiven çıkma gibi aktivitelerde fonksiyon kaybı gözlemlenir.

İnferior gluteal sinir patolojisine neden olan etiyolojik faktörler arasında; sinirin endometriyozis dokusu tarafindan kompresyonu, herediter multipl ekzostozis, piriformis kas hipertrofisi ve hematomu, rekürren kolorektal karsinom ve kas içi enjeksiyon bildirilmiştir. ${ }^{[25]}$

Tanısında, klinik bulgular ve elektrofizyolojik incelemenin yanı sıra, MR görüntülemede, sinir dokusundaki anormalliklerin direkt görüntülenmesi güç olduğundan, gluteus maksimus kasındaki denervasyon bulguları da yol gösterici olabilir.

\section{OBTURATOR SINIR}

Obturator sinir, L2, L3 ve L4 seviyelerinde, lomber pleksusun ventral dallarından köken alır. Lomber köklerden köken alan diğer sinirler gibi, iliopsoas kasını penetre ederek ve distale doğru iliopektineal hattan ilerleyerek, obturator foramen seviyesinde anterior ve posterior dallarını verir. Anterior dalı adduktor brevis kasının anteriorundan ilerleyerek kalça eklemini innerve edip, grasilis kasına, adduktor brevis ve longus kaslarına ve daha az sıklıkta pektineus kasına motor dallar verir. Ayrıca, uyluk mediyalinin duyusunu sağlar. Posterior dalı ise, adduktor brevis kasının posteriorundan ilerleyerek, diz ekleminin innervasyonuna katkıda bulunur; ayrıca, eksternal obturator, adduktor magnusun adduktor komponenti ve bazen de adduktor brevis kaslarına motor dallar verir. Posterior dal, diz mediyalinin duyusal innervasyonunu da sağlar.

Obturator sinirin motor fonksiyonları, temel olarak kalça ve uyluğun adduksiyonunu sağlar. Ayrıca, diz fleksiyonu, tibianın mediyal rotasyonu, kalça fleksiyonu ve uyluğun eksternal rotasyonunda yardımcıdır. Obturator sinir nöropatisi durumunda, bu fonksiyonlarda azalma ve uyluk mediyalinde duyu kaybı gözlenebilir.

Obturator nöropati, göreceli olarak nadir bir durum olup, en sık pelvik travma, pelvik ve jinekolojik cerrahide 
görülür. Obturator sinir nöropatisinde rol oynayan diğer etiyolojik faktörler, Tablo 3'te listelenmiştir.

Obturator sinirin MR görüntüleme ile incelenmesinde, adduktor kompartmanda denervasyona bağlı bulgular görülebilir. Kaslardaki denervasyona bağlı sinyal intensite değişiklikleri, strain ile karıştırılmamalıdır. Denervasyona bağlı değişiklikler, diffüz sinyal değişiklikleri üretir ve fasyal planlar korunmuştur; strain durumunda, fokal bulgular fasyal tutulumla birlikte görülür. MR görüntülemede, kitle etkisine neden olan hematom, kırık, bursa, tümör, metastaz, implant veya kemik çimentosu gibi oluşumlar da belirlenebilir.

Tablo 3. Obturator mononöropati etiyolojik faktörler ${ }^{[25]}$

Asetabular labral kist

Hipogastrik arter anevrizması

Sezaryen doğum

Kollajen enjeksiyonu

Diyabetes mellitus

Femoral arter anjiyoplastisi

Doğum sırasında forseps kullanımı

Yüksek performanslı atletizm

Kalça artroplastisi

Idiyopatik

Laparaskopik radikal prostatektomi ve sistektomi

Laparaskopik retroperitoneal cerrahi

Laparoskopik tübal oklüzyon

Lipomatozis infiltrasyonu

Litotomi pozisyonu

Lokal anestezi

Obturator kanalda metastatik lezyon

Miyozistis ossifikans

Obturator herni

Pelvik lenfadenektomi

Pelvik cerrahi

Pelvik travma

Postpartum

Retroperitoneal hematom

Rüptüre abdominal aort anevrizması

Sinovial kist

Total kalça artroplastisi

Total diz artroplastisi

Vajinal tape uygulaması (inkontinans)
Obturator nöropatinin tedavisi öncelikle konservatiftir. Dirençli olgularda, sinir bloğu, nöroliz ve fasyal rezeksiyon düşünülebilir.

\section{LATERAL FEMORAL KUTANÖZ SINIR}

Lateral femoral kutanöz sinir (LFKS), L2 ve L3 seviyelerinden köken alan, saf duyusal bir sinirdir. iliopsoas kasını geçerek iliakus kasının anteriorunda seyreder ve inguinal bağ seviyesine ulaşır. Bu seviyede, anterior superior iliak çıkıntının yaklaşık $1 \mathrm{~cm}$ mediyalinden, inguinal bağı geçer. Sinir burada, inguinal bağın altından (lakuna muskulorum), içinden veya üzerinden geçebilir. İnguinal bağ seviyesinin distalinde, sartorius kası üzerinde, anterior ve posterior dallara ayrılır. Anterior dalı, inguinal bağın yaklaşık $10 \mathrm{~cm}$ distalinde yüzeyelleşir ve uyluk ön ve lateral bölgelerinin, diz seviyesine kadar duyusal innervasyonunu sağlar. Bu dalın terminal lifleri, femoral sinirin anterior kutanöz dalları ve safen sinirin infrapatellar dalları ile temas kurarak, peripatellar pleksusu oluşturur. Posterior dalı ise, fasya latayı penetre ederek, trokanter majör seviyesinden uyluk ortasına kadar olan bölgenin lateral ve posterior yüzeylerinin duyusal innervasyonunu sağlar.

LFKS nöropatisine "meraljia parestetika" adı verilir. Bu durum, daha önce Hager ${ }^{[28]}$ tarafından tanımlanmış olmasına karşın, ilk olarak Roth ${ }^{[29,30]}$ ve Bernhardt ${ }^{[29,31]}$ tarafından adlandırılmıştır.

LFKS nöropatisinin etiyolojisinde rol oynayan faktörler, idiyopatik ve iyatrojenik olmak üzere iki grupta incelenebilir. İdiyopatik grupta, sinirin kompresyonuna neden olan mekanik faktörler ve metabolik bozukluklar yer alır. Bunlar; obezite (VKi $\geq 30)$, gebelik, sıkı giysiler, emniyet kemerleri, direkt travma, kas spazmı, skolyoz, iliakus kas hematomu ve ekstremite uzunluk değişimleri olarak bildirilmiştir. ${ }^{[28]} \mathrm{Bu}$ gruptaki metabolik bozukluklar ise, diabetes mellitus, alkolizm ve kurşun zehirlenmesidir. ${ }^{[28]}$ İyatrojenik etkenler, kalça artroplastisi, omurga cerrahisi, iliak kemik grefti alınması, açık ve laparoskopik appendektomi, sezaryen, epidural analjezi, obstetrik ve jinekolojik cerrahi girişimler olarak bildirilmiştir. ${ }^{[28]}$ LFKS, sıklıkla inguinal bağ seviyesinde mekanik kompresyona uğrar.

Hastalar, uyluk laterali veya anterolateralinde ağrı, yanma, uyuşukluk, üşüme hissi, titreme hissi (cep telefonu titreşimine benzer şekilde) gibi yakınmalarla başvurabilir. Ayrıca, yakınmalarının uzun süre ayakta durma ve yürümeyle arttığını ve oturmakla azaldığını belirtebilirler. Semptomlar sıklıkla hafif düzeyde olmakla birlikte, bazen şiddetli ve fonksiyonel kısıtlanmaya neden olabilecek bulgulara rastlanabilir. Çocuk yaş grubunda hastalık, genellikle bilateral ve daha ağrıIı olup, sıklıkla cerrahi dekompresyon gerektirir. Klinik 
incelemede; pelvik kompresyon testi (pelvik kompresyon ile inguinal bağda gevşeme olması sonucunda hastanın şikayetlerinde azalma olması, pozitif olarak kabul edilir), tinel bulgusu gibi yöntemler kullanılabilir. Nörofizyolojik incelemede SSEP ve duyusal sinir ileti hızı incelemeleri kullanılabilir. LFKS patolojilerinde, $M R$ incelemelerinde sinirin görüntülenmesi oldukça zor olmakla birlikte, MR nörografisi ile başarılı sonuçlar bildirilmiştir. ${ }^{[32]} \mathrm{Ek}$ olarak, inguinal bağ seviyesinde bir lokal anestetik ile sinir bloğu uygulaması yoluyla semptomların gerilemesi, pozitif sinir bloğu testi olarak kabul edilebilir.

Tedavide, konservatif ve cerrahi yöntemler kullanılabilir. Konservatif yöntemlerde, sıkışma bölgesinin korunması ve basının ortadan kaldırılması esas olup; anti-inflamatuvar tedavi, fizik tedavisi gibi yöntemler sıklıkla tercih edilir. Lokal anestetik ve kortikosteroid ile sinir bloğu ya da radyofrekans (pulsed) uygulaması, önerilen yöntemler arasındadır. ${ }^{[28]}$ Meraljia parestetika hastalarında fizik tedavi ve rehabilitasyon uygulamalarında, manuel terapi, kinesiotaping ve akapunktur uygulamaları da bildirilmiştir. ${ }^{[28]}$ Cerrahi dışı tedavi yöntemlerinin başarısız olduğu olgularda, hem nöroliz ve hem de rezeksiyon yöntemleri ile başarılı sonuçlar bildirilmiştir. ${ }^{[28]}$

\section{ILIOINGUINAL, ILIOHIPOGASTRIK VE GENITOFEMORAL SINIRLER}

Ilioinguinal ve iliohipogastrik sinirler, üst lomber pleksusun L1 seviyesindeki liflerinden köken alan homolog sinirlerdir. Illioinguinal sinir, L1 kökü seviyesinden ayrıldıktan sonra, psoas kasının lateralinden ilerleyerek kuadratus lumborum ve iliakus kaslarını çaprazlar, internal oblik ve transvers abdominal kasları innerve eder ve iliohipogastrik sinir ile temas sağlar. Duyusal dalları, uyluk proksimal mediyal bölgesine, erkeklerde penis ve üst skrotal bölgeye (anterior skrotal sinir), kadınlarda pubis ve labia majör bölgesine (anterior labial sinir) dağılır. illiohipogastrik sinir, L1 seviyesinden ve köken alarak (T12 seviyesinden bazı liflerin katılımıyla), psoas kasının anteriorundan ilerleyerek iliak kanat bölgesine ulaşır ve pubis bölgesinde sonlanır. Motor dalları, internal oblik ve transvers abdominal kasları innerve eder. Duyusal dalları, gluteal bölgenin laterali ve anterior abdominal bölgeyi innerve eder. Genitofemoral sinir, L1 ve L2 seviyelerinden köken alır ve psoas kası boyunca ilerleyerek, genital ve femoral dallara ayrilır. Genital dal, inguinal kanaldan geçerek, erkeklerde skrotal cilt bölgesini, kadınlarda ise uterus round ligament, mons pubis ve labia major bölgesine dağılır. Femoral dal ise, inguinal bağın altından geçtikten sonra, proksimal anterior uyluk bölgesinin duyusal innervasyonunu sağlar. Genitofemoral sinirin motor lifleri (genital dal), kremaster refleksindeki kontraksiyonları sağlar.

İlioinguinal nöropatili hastalar, genellikle kasık bölgesinde (proksimale ve iç yüzeye doğru yayılan) ağrıdan yakınırlar. ilioinguinal mononöropatinin etiyolojisinde; herniyorafi (veya buna bağlı skar dokusu ve yapışıklıklar), pelvik ve jinekolojik cerrahi, laparoskopik cerrahi, gebelik, nefrektomi ve iliak kanadın mediyal duvarından kemik grefti alınması sayılabilir. Illioinguinal nöropatinin ayırıcı tanısında, iliohipogastrik ve genitofemoral sinir nöropatileri de düşünülmelidir.

İliohipogastrik nöropati hastaları, kasık bölgesi ve suprapubik alanda ağrı ve duyu kaybından şikayetçidirler. Illiohipogastrik mononöropatinin etiyolojisinde; pelvik ve jinekolojik cerrahi ile ilişkili travma, herniyorafi ve laparoskopik cerrahinin rol oynadığı bildirilmiştir. ${ }^{[25]}$

Genitofemoral sinir nöropatisinde, kasık mediyal ve inferior bölgesinde ve uyluk proksimal anterior ve mediyalinde nöropatik ağrı ile birlikte, duyusal kayıp söz konusudur. Genitofemoral mononöropatinin etiyolojisinde; genellikle pelvik ve jinekolojik cerrahi, endoskopik herniyorafi rol oynamakla birlikte, bazı hastalarda herhangi bir neden saptanamayabilir. ${ }^{[25]}$

\section{POSTERIOR FEMORAL KUTANÖZ SINIR}

Posterior femoral kutanöz sinir (PFKN), sakral pleksustan köken alır, siyatik sinir eşliğinde pelvisi terk ederek gluteal bölgenin posterior ve mediyal alanlarına, skrotum ve labiaların bir kısmına, diz seviyesine kadar uyluk posterior yüzeyine dağılım gösterir. PFKN tuzak nöropatisi ile nadir olgular bildirilmiştir. ${ }^{[29]} \mathrm{Bu}$ hastalardaki duyusal bulgular siyatalji ile karışabilir.

\section{KAYNAKLAR}

1. Dawson DM, Hallett M, Wilbourn AJ. Perioperative nerve lesions. In: Dawson DM, Hallett M, Wilbourn AJ, editors. Entrapment neuropathies, 3rd ed. Philadelphia: LippincottRaven; 1999. p.433-42.

2. Montag TW, Mead PB. Postpartum femoral neuropathy. J Reprod Med 1981;26(11):563-6.

3. al Hakim M, Katirji B. Femoral mononeuropathy induced by the lithotomy position: a report of 5 cases with a review of literature. Muscle Nerve 1993;16(9):891-5.

4. Reinstein L, Eckholdt JW. Sciatic nerve compression by preexisting heterotopic ossification during general anesthesia in the dorsal lithotomy position. Arch Phys Med Rehabil 1983;64(2):65-8.

5. Weber ER, Daube JR, Coventry MB. Peripheral neuropathies associated with total hip arthroplasty. J Bone Joint Surg Am 1976;58(1):66-9.

6. Petchprapa CN, Rosenberg ZS, Sconfienza LM, Cavalcanti CF, Vieira RL, Zember JS. MR imaging of entrapment neuropathies of the lower extremity. Part 1. The pelvis and hip. Radiographics 2010;30(4):983-1000. CrossRef 
7. Chappell KE, Robson MD, Stonebridge-Foster A, Glover A, Allsop JM, Williams AD, Herlihy AH, Moss J, Gishen P, Bydder GM. Magic angle effects in MR neurography. AJNR Am J Neuroradiol 2004;25(3):431-40.

8. Dawson DM, Hallett $M$, Wilbourn AJ. Sciatic nerve entrapment. In: Dawson DM, Hallett M, Wilbourn AJ, editors. Entrapment neuropathies, 3rd ed. Philadelphia: LippincottRaven; 1999. p.264-9.

9. Schmalzried TP, Amstutz HC, Dorey FJ. Nerve palsy associated with total hip replacement. Risk factors and prognosis. J Bone Joint Surg Am 1991;73(7):1074-80.

10. Michel F, Decavel P, Toussirot E, Tatu L, Aleton E, Monnier G, Garbuio P, Parratte B. Piriformis muscle syndrome: diagnostic criteria and treatment of a monocentric series of 250 patients. Ann Phys Rehabil Med 2013;56(5):371-83. CrossRef

11. Michel F, Decavel P, Toussirot E, Tatu L, Aleton E, Monnier G, Garbuio P, Parratte B. The piriformis muscle syndrome: an exploration of anatomical context, pathophysiological hypotheses and diagnostic criteria. Ann Phys Rehabil Med 2013;56(4):300-11. CrossRef

12. Yeoman $\mathrm{W}$. The relation of the arthritis of the sacroiliac joint to sciatica, with an analysis of 100 cases. Lancet 1928;2:1119-22.

13. Robinson DR. Pyriformis syndrome in relation to sciatic pain. Am J Surg 1947;73(3):355-8.

14. Hernando MF, Cerezal L, Pérez-Carro L, Abascal F, Canga A. Deep gluteal syndrome: anatomy, imaging, and management of sciatic nerve entrapments in the subgluteal space. Skeletal Radiol 2015;44(7):919-34. CrossRef

15. Papadopoulos EC, Khan SN. Piriformis syndrome and lowback pain: a new classification and review of the literature. Orthop Clin North Am 2004;35(1):65-71.

16. Foster MR. Piriformis syndrome. Orthopedics 2002;25(8):821-5.

17. Martin HD, Kivlan BR, Palmer IJ, Martin RL. Diagnostic accuracy of clinical tests for sciatic nerve entrapment in the gluteal region. Knee Surg Sports Traumatol Arthrosc 2014;22(4):882-8. CrossRef

18. Russell JM, Kransdorf MJ, Bancroft LW, Peterson JJ, Berquist TH, Bridges MD. Magnetic resonance imaging of the sacral plexus and piriformis muscles. Skeletal Radiol 2008;37(8):709-13. CrossRef

19. Filler AG, Haynes J, Jordan SE, Prager J, Villablanca JP, Farahani K, McBride DQ, Tsuruda JS, Morisoli B, Batzdorf $U$, Johnson JP. Sciatica of nondisc origin and piriformis syndrome: diagnosis by magnetic resonance neurography and interventional magnetic resonance imaging with outcome study of resulting treatment. J Neurosurg Spine 2005;2(2):99-115.
20. Fanucci E, Masala S, Sodani G, Varrucciu V, Romagnoli A, Squillaci E, Simonetti G. CT-guided injection of botulinic toxin for percutaneous therapy of piriformis muscle syndrome with preliminary MRI results about denervative process. Eur Radiol 2001;11(12):2543-8.

21. Martin HD, Shears SA, Johnson JC, Smathers AM, Palmer IJ. The endoscopic treatment of sciatic nerve entrapment/ deep gluteal syndrome. Arthroscopy 2011;27(2):172-81. CrossRef

22. Pirouzmand F, Midha R. Subacute femoral compressive neuropathy from iliacus compartment hematoma. Can J Neurol Sci 2001;28(2):155-8.

23. Nakao A, Sakagami K, Mitsuoka S, Uda M, Tanaka N. Retroperitoneal hematoma associated with femoral neuropathy: a complication under antiplatelets therapy. Acta Med Okayama 2001;55(6):363-6.

24. Robinson DE, Ball KE, Webb PJ. Iliopsoas hematoma with femoral neuropathy presenting a diagnostic dilemma after spinal decompression. Spine (Phila Pa 1976) 2001;26(6):E135-8.

25. Donofrio PD. Common mononeuropathies of the lower extremities. In: Donofrio PD, editor. Textbook of peripheral neuropathy. Demos Medical Publishing; 2012. p.27-39.

26. Ramesh M, O'Byrne JM, McCarthy N, Jarvis A, Mahalingham $\mathrm{K}$, Cashman WF. Damage to the superior gluteal nerve after the Hardinge approach to the hip. J Bone Joint Surg $\mathrm{Br}$ 1996;78(6):903-6.

27. Collinge C, Coons D, Aschenbrenner J. Risks to the superior gluteal neurovascular bundle during percutaneous iliosacral screw insertion: an anatomical cadaver study. J Orthop Trauma 2005;19(2):96-101.

28. Cheatham SW, Kolber MJ, Salamh PA. Meralgia paresthetica: a review of the literature. Int J Sports Phys Ther 2013;8(6):883-93.

29. Dawson DM, Hallett $M$, Wilbourn AJ. Miscellanous uncommon syndromes of the lower extremity. In: Dawson DM, Hallett M, Wilbourn AJ, editors. Entrapment neuropathies, 3rd ed. Philadelphia: Lippincott-Raven; 1999. p.369-79.

30. Roth WK. Meralgia paraesthetica. Berlin: S. Karger; 1895.

31. Bernhardt M. Uber isoliert in gebiete des nervus cutaneus femoris externus vorkommende paresthesia. Neurol Centralbl 1895; 14:242.

32. Chhabra A, Del Grande F, Soldatos T, Chalian M, Belzberg AJ, Williams EH, Jalali FS, Thawait GK, Eng J, Carrino JA. Meralgia paresthetica: 3-Tesla magnetic resonance neurography. Skeletal Radiol 2013;42(6):803-8. CrossRef 